\title{
Aplikasi Rekomendasi Lokasi Pariwisata Menggunakan Metode Profile Matching
}

\author{
Bayu Adhitia Wardana*1, Zamah Sari ${ }^{2}$, Denar Regata Akbi ${ }^{3}$ \\ 1,2,3 Teknik Informatika/Universitas Muhammadiyah Malang \\ bayu.adhitia@gmail.com¹, abdzamahsari@gmail.com², dnarregata@umm.ac.id ${ }^{3}$
}

\begin{abstract}
Abstrak
Lokasi Pariwisata atau objek wisata adalah sebuah tempat rekreasi atau tempat untuk berwisata. Lokasi Pariwisata dapat berupa objek wisata alam eperti gunung, danau, sungai, pantai dan juga bisa berupa bangunan seperti museum, benteng dan situs peninggalan sejarah. Merancang dan merealisasikan serta menguji aplikasi Android yang dapat memberikan rekomendasi lokasi pariwisata serta panduan wisata Kota Banjarmasin dengan menggunakan metode Profile Matching untuk mencari atau mendapatkan rute terpendek dalam radius tertentu yang akan ditampilkan pada Google Map API. Tujuan dari penelitian ini adalah mengimplementasikan Metode Profile Matching untuk mencari atau mendapatkan rute terpendek dalam radius tertentu yang akan ditampilkan pada Google Map API. Tujuan dari penelitian ini adalah mengimplementasikan Metode Profile Matching untuk bisa merekomendasi lokadi pariwisata dalam radius yang telah ditentukan oleh pengguna sehingga pengguna dapat lebih efektif dan cepat dalam mencapai ke tempat lokasi pariwisata yang telah di tentukan dan pengguna bisa memperikirakan bagaimana pengguna akan menuju ke lokasi pariwisata tersebut. Dalam aplikasi juga telah di sediakan berupa petunjuk arah menuju ke lokasi pariwisata yang telah dipilih pengguna menggunakan Google Map API beserta rute alternative jika terjadi sesuatu yang membutuhkan pengalihan rute.
\end{abstract}

Kata Kunci: Lokasi Pariwisata, Google Map API, Profile Matching

\begin{abstract}
The tourism location or tourist attraction is a recreation place or a place to travel. Tourism location can be a natural attraction such as mountains, lakes, rivers, beaches and also can be buildings such as museums, forts and historical heritage sites. Designing and realizing and testing Android applications that can provide recommendations of tourism locations and travel guides of Banjarmasin City by using the Profile Matching method to find or get the shortest route in the radius will be displayed on the Google Map API. The purpose of this research is to implement the Profile Matching method to recommend tourism in a radius that has been determined by the user so that the user can be more effective and fast in reaching the location Tourism that has been defined and the user can be able to identify how the user will be heading to the location of the tourism. In the application also has been provided in the form of directions to the tourism site that has been selected by users using the Google Map API along with alternative routes if something happens that requires switching route.
\end{abstract}

Keywords: Tourism Location, Google Map API, Profile Matching

\section{Pendahuluan}

Pada penelitian ini penulis akan merancang serta membangun sistem rekomendasi serta panduan wisata kota Banjarmasin yang ditujukan untuk wisatawan yang membutuhkan bantuan dalam pemilihan rujukan spot wisata dan ulasan informasi disekitarnya dengan menggunakan metode Profile Matching Metode Profile Matching digunakan untuk menentukan rekomendasi berdasarkan jarak, tarif atau tiket dan fasilitas pendukung yang disediakan atau terdapat disekitar objek wisata yang direkomendasikan

\subsection{Profile Matching}

Pengertian Profile Matching dalam penentuan kenaikan suatu jabatan dapat dijelaskan sebagai proses membandingkan antara kompetensi individu ke dalam kompetensi jabatan sehingga dapat diketahui perbedaan kompetensinya atau yang disebut juga gap, semakin kecil 
gap yang dihasilkan maka bobot nilainya semakin besar berarti memiliki peluang lebih besar untuk karyawan menempati posisi tersebut. Profile Matching merupakan suatu proses yang sangat penting dalam manajemen SDM di mana terlebih dahulu ditentukan kompetensi atau kemampuan dasar yang diperlukan oleh suatu jabatan. Kompetensi kemampuan tersebut haruslah dapat dipenuhi oleh pemegang atau calon yang akan dinilai kinerjanya [1].

\subsection{Google Map API}

Google Map Service adalah sebuah layanan peta global virtual gratis dan online yang disediakan oleh perusahaan Google. Google Mapi menawarkan peta yang diperoleh dari gambar satelit untuk pemetaan permukaan dan jalur di seluruh dunia. Google Maps juga menawarkan pencarian suatu tempat dan rute perjalanan [2]. Google Maps Application Programing Interface adalah sebuah layanan yang diberikan oleh Google kepada para pengguna dan pengembang aplikasi untuk memanfaatkan Google Map dalam mengembangkan aplikasi yang di dalamnya membutuhkan panduan rute dan pencarian lokasi. Google Maps API menyediakan beberapa fitur untuk memanipulasi peta dan menambah konten melalui berbagai jenis layanan yang dimiliki serta mengijinkan kepada pengembang untuk membangun aplikasi. Pengguna dapat memanfaatkan layanan-layanan yang ditawarkan oleh Google Maps setelah melakukan registrasi dan mendapatkan Google Maps API Key. Google menyediakan layanan ini secara gratis kepada pengguna di seluruh dunia [2].

\subsection{FireBase}

Firebase merupakan suatu layanan Database As a Service yang disediakan oleh Google sebagaiisarana pengembanganiaplikasi yangimembutuhkan database realtime. Firebase merupakan platform untuk aplikasi realtime. Ketika data berubah, maka aplikasi dengan firebase akan meng-update secara langsung melalui setiap device perangkat baik web atau mobile. Firebase mempunyai library yang lengkap untuk sebagian besar platform web dan mobile dan dapat digabungkan dengan berbagai framework seperti Java Script, AngularJS, dan lain-lain. Application Programming Interface (API) untuk menyimpan dan sinkronisasi data akan disimpan sebagai susunan data dalam bentuk JSON pada cloud dan akan disinkronisasi secara realtime. Layanan pada Firebase meliputi autentikasi pengguna, pengaturan keamanan, dan hosting. Perubahan data pada satu client akan disinkronisasi pada semua client yang terdaftar ke data tersebut dalam hitungan milidetik. Kelebihan dari Firebase adalah dapat menerima data dari 1 juta perangkat secara bersamaan.

\subsection{Aplikasi Android dan MIT APP Inventor}

Android adalah sebuah sistem operasi untuk perangkat mobile berbasis linuxyang mencakup sistem operasi, middleware dan aplikasi. Android menyediakan sistem operasi yang terbuka bagi para pengembang untuk menciptakan aplikasi. Android diluncurkan untuk umum pada musim gugur di tahun 2008. Android sangat berkembang pesat di industri karena dua aspek utama yaitu bersifat opensource dan model arsitekturya. Sebagai sebuah proyek bersifat opensource, memungkinkan android untuk sepenuhnya dipahami dan dianalisis mengenai fitur, penyelesaian pada bug program hingga hardware.

MIT APP Inventor merupakan model baru dalam pemrograman android, dimana tidak lagi menggunakan penulisan source code seperti pada umumnya, melainkan dengan menggunakan puzzle drag and drop yang memudahkan pengguna dalam membangun aplikasi android.

\section{Metode Penelitian}

Metodologi merupakan tahapan yang dilakukan oleh peneliti. Tahapan ini dimulai dari perumusan masalah hingga kesimpulan, yang nantinya akan membentuk sebuah alur yang sistematis yang akan berfungsi sebagai acuan penelitian agar hasil yang dapatkan tidak menyimpang dari tujuan yang telah ditetapkan. Pada penelitian ini metode penelitian yang ditempuh dimulai analisa kebutuhan, desain sistem, pembuatan program, testing dan pengujian.

\subsection{Pengambilan Data}

Pada tahap ini akan mengidentifikasikan permasalahan yang terjadi dan dialami oleh pengelola objek wisata di Kota Banjarmasin sehingga diperoleh data yang valid mengenai keluhan ataupun saran agar sistem ini dapat berfungsi optimal. Dengan mengidentifikasikan

REPOSITOR, Vol. 2, No. 6, Juni 2020: 727-736 
masalah secara terarah maka penelitian yang dilakukan akan memperoleh hasil yang sesuai dengan tujuan yang telah dipaparkan.

Permasalahan yang terjadi adalah terkadang objek wisata tertentu tidak terindex oleh search engine dan kurang mendapat perhatian dari wisatawan dikarenakan minimnya informasi, selain itu untuk membuat suatu objek wisata menjadi lebih menarik tentunya dibutuhkan informasi tambahan seperti akses menuju objek tersebut, ketersediaan fasilitas pendukung seperti hotel dan resto serta pusat oleh-oleh atau seouvenir disekitar spot wisata dan rujukan kuliner.

\subsection{Pemodelan data}

Proses pengumpulan data dilakukan untuk mengetahui parameter apa saja yang dapat digunakan dalam penelitian ini, data yang akan digali oleh peneliti adalah tarif yang ditawarkan dari spot wisata, fasilitas pendukung, jarak ke pusat kota Banjarmasin serta koordinat dari tempat tersebut dan data ini dapat diperoleh dengan melakukan wawancara, survey secara langsung ke spot wisata. Data yang diperoleh dapat digunakan sebagai acuan membuat inputan pada bagian penyimpanan data [2] dan dibagi menjadi dua bagian yaitu core factor dan secondary factor. Seperti yang ditunjukkan pada Tabel 1 dan Tabel 2.

\begin{tabular}{ccc}
\multicolumn{4}{c}{ Tabel } & Tabel & Penentuan Skor \\
\hline No & Skor & Keterangan \\
\hline 1 & 5 & sangat \\
2 & 4 & cukup \\
3 & 3 & sedang \\
4 & 2 & kurang \\
5 & 1 & tidak \\
\hline
\end{tabular}

Tabel 2. Contoh Model Alternatif dan Kriteria

\begin{tabular}{cccc}
\hline No Alternatif(objek wisata) & \multicolumn{1}{c}{ Kriteria } & Skor \\
\hline & $\begin{array}{l}\text { jarak dari pengguna aplikasi (semakin } \\
\text { dekat skornya semakin tinggi) } \\
\text { kisaran harga tiket atau tarif (semakin } \\
\text { tinggi skornya semakin mahal) } \\
\text { fasilitas disekitar (semakin tinggi skornya }\end{array}$ & 5 \\
& semakin banyak fasilitas serta layanan & 5 \\
& Penyedia jasa A & $\begin{array}{l}\text { yang disediakan) } \\
\text { ketersediaan objek pendukung (semakin } \\
\text { tinggi skornya semakin banyak objek } \\
\text { wisata yang berkaitan) } \\
\text { akses jalan dan angkutan (semakin tinggi } \\
\text { skornya semakin banyak) }\end{array}$ & 4 \\
\hline
\end{tabular}

Data yang diperoleh berupa:

1. Dataiprimer yangidiperoleh dari pengamatan danipengumpulan data dari media sosial daniwebsite penyedia ulasan wisata.

2. Dataisekunderimerupakanidata yang dihasilkan dari pemrosesaniaplikasi berupa rekomendasi objekiyangitelahidijelaskanidi pendahuluan.

3. Pada bagian di atas yang digunakan sebagai core factor adalah jarak dari pengguna aplikasi, harga tiket, fasilitas disekitar dan ketersediaan fasilitas pendukung, secondary factor yang digunakan adalah akses jalan.

\subsection{Flowchart Program}

Pada tahap ini akan dijelaskan alur serta langkah yang ditempuh gunamenjawab tujuan pe nelitiandan agar tidak menyimpang dari tujuan maka perlu didefinisikan perancangan yang jelas.

Rul Based System (basis pengetahuan) merupakan elemen utama dari metode Profile Matching untuk memberikan hasil maksimal.

Pada Gambar 1 dijelaskan Langkah-langkah yang dilalui penulis sehingga penelitian dapat dikerjakan, dimulai dari pengumpulan data kemudia data tersebut diubah ke dalam bentuk yang dapat diproses menggunakan Profile Matching untuk kemudian disimpan di database, dari 
database tersebut program android akan mengambil data untuk diproses dengan metode Profile Matching.

Profile Matching merupakan sebuah mekanisme pengambilan keputusan dengan mengas umsika bahwa terdapat tingkat variabel prediktor yang ideal yang harus dimiliki oleh individu, bukan tingkat minimal yang harus dipenuhi atau dilewati. Dalam profile matching dilakukan identifikasi terhadap suatu kelompok baik maupun buruk. Para individu dalam kelompok tersebut diukur menggunakan beberapa kriteria penilaian [4]. Kriteria rekomendasi objek wisata yang maksud antara lain adalah Jarak, tarif atau harga tiket yang ditawarkan, fasilitas pendukung dan akses menuju objek. Dari masing-masing kriteria ditentukan bobot dengan total bobot dari keseluruhan kriteria adalah 5, bobot yang digunakan berdasarkan tingkat kepentingan dalam pemberian rekomendasi.

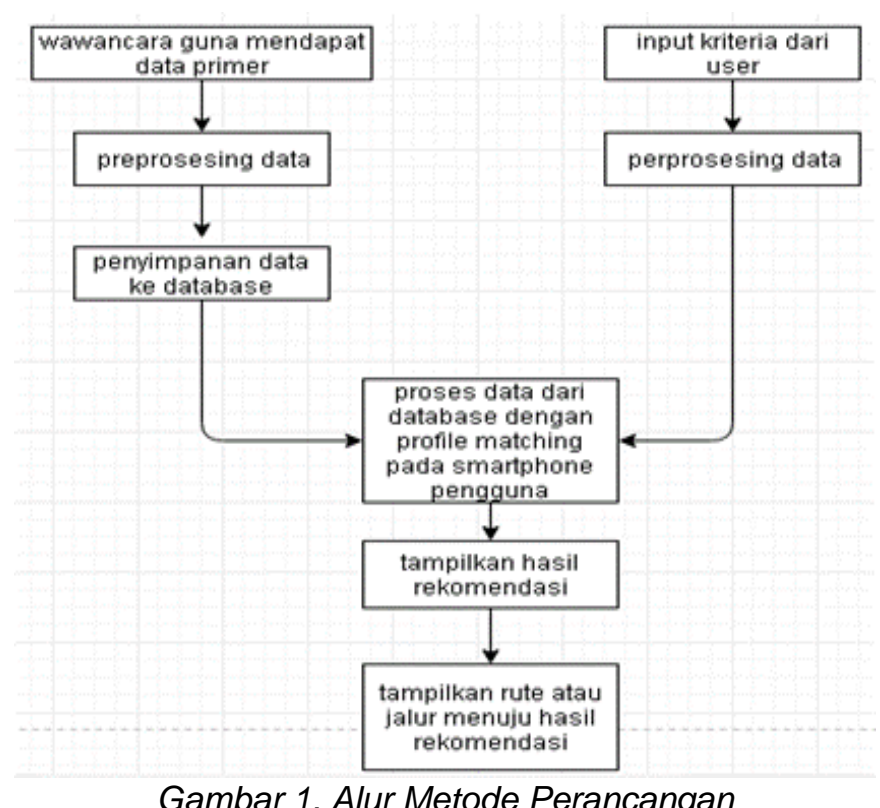

Gambar 1. Alur Metode Perancangan

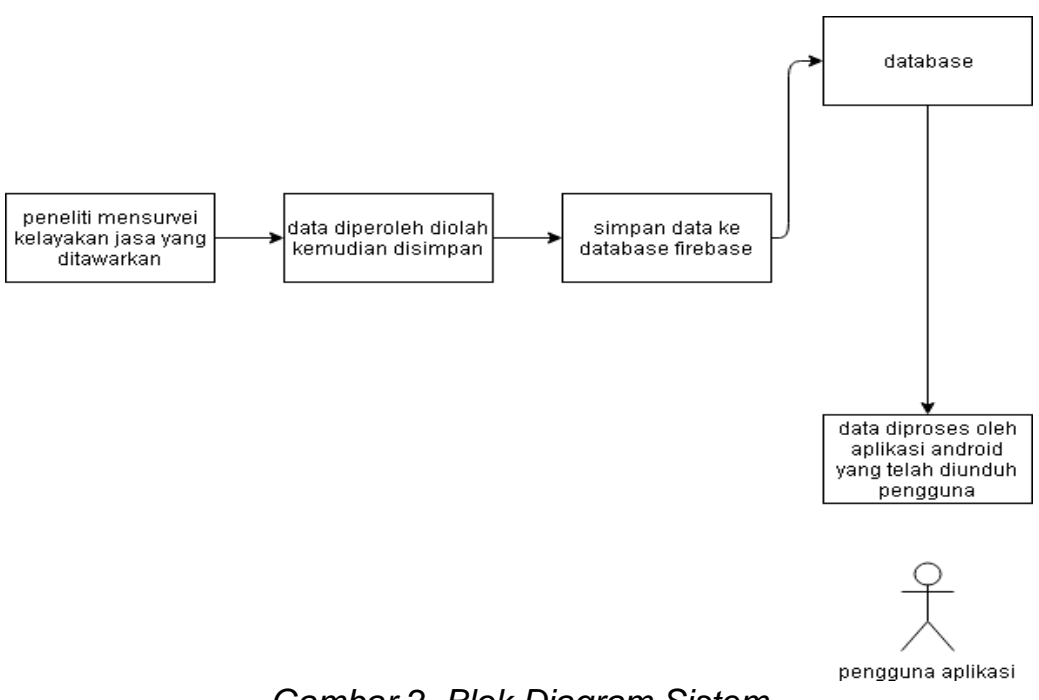

Pada Gambar 2 dijelaskan bila aplikasi ini menyimpan data objek dan segala informasi fasilitas pendukung yang terdaftar dalam sistem aplikasi, data tersebut diakses oleh aplikasi pada smartphone pengguna untuk memperoleh data rekomendasi yang diproses menggunakan metode Profile Matching sehingga dioutputkan suatu hasil rekomendasi kepada pengguna. 
Proses perhitungan pada metode Profile Matching, diawali dengan pendefinisian nilai minimum untuk setiap variabel-variabel penilaian. Selisih setiap nilai data testing terhadap nilai minimum masing-masing variabel, merupakan gap yang kemudian diberi bobot. Bobot setiap variabel akan dihitung rata-rata berdasarkan kelompok variabel Core Factor dan Secondary Factor. Komposisi Core Factor ditambah Secondar Factor adalah 100\%, tergantung dari kepentingan pengguna metode ini. Tahap terakhir dari metode ini, adalah proses akumulasi nilai Core Factor dan Secondar Factor berdasarkan nilai-nilai variabel data testing.

Pembobotan pada metode Profile Matching, merupakan nilai pasti yang tegas pada nila tertentu karena nilai-nilai yang ada merupakan anggota himpunan tegas atau Crisp Set. Di dalam himpunan tegas, keanggotaan suatu unsur di dalam himpunan dinyatakan secara tegas, apakah objek tersebut anggota himpunan atau bukan dengan menggunakan fungsi karakteristik. Langkah-langkah metode profile matching adalah:

1. Menentukan variabel data-data yang dibutuhkan.

2. Menentukan aspek-aspek yang digunakan untuk penilaian.

3. Pemetaan Gap profil.

4. Gap $=$ Profil Minimal - Profil data tes

5. Setelah diperoleh nilai Gap selanjutnya diberikan bobot untuk masing-masing nilai Gap. Perhitungan dan pengelompokan Core Factor dan Secondary Factor. Setelah menentukan bobot nilai gap, kemudian dikelompokan menjadi 2 kelompok yaitu:

1. Core Factor atau Faktor Utama, yaitu merupakan kriteria atau kompetensi yang paling penting atau menonjol atau paling dibutuhkan oleh suatu penilaian yang diharapkan dapat memperoleh hasil yang optimal.

2. Secondary Factor atau faktor pendukung, yaitu merupakan item-item selain yang ada pada corefactor, atau dengan kata lain merupakan faktor pendukung yang kurang dibutuhkan oleh suatu penilaian.

6. Perhitungan nilai total. Nilai Total diperoleh dari prosentase core factor dan secondary factor yangidiperkirakan berpengaruh terhadap hasil tiap-tiap profil.

7. Perhitungan penentuan ranking. HasiliAkhir dari proses profile matching adalah ranking. Penentuan ranking mengacu pada hasil perhitungan tertentu.

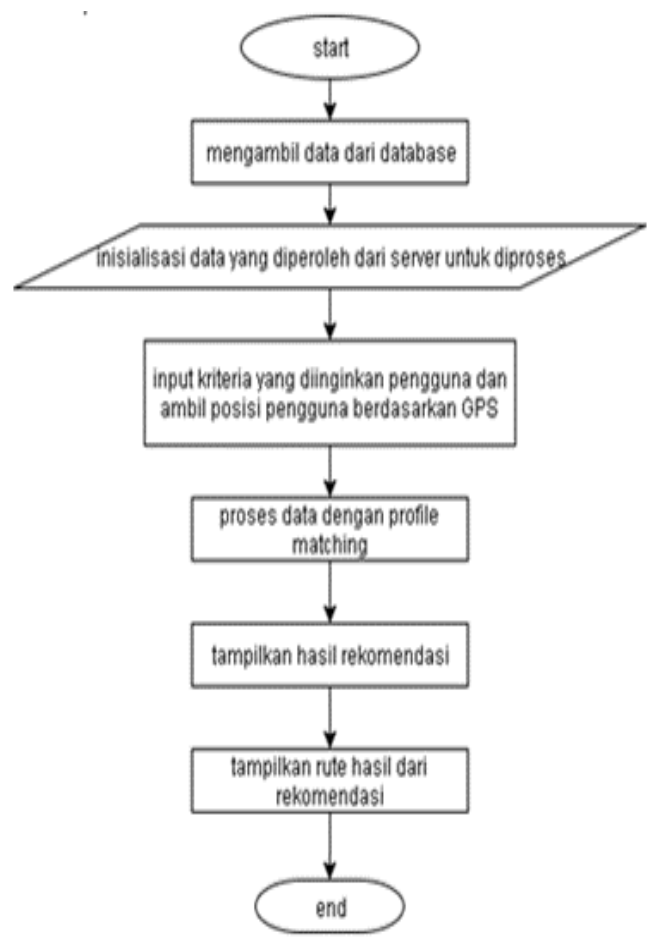

Gambar 3. Flowchart Program

Pada Gambar 3 dijelaskan alur program akan menanyakan kriteria yang dikehendaki oleh pengguna aplikasi ini sehingga dapat disesuaikan ketika pemprosesan menggunakan metode Profile Matching, kemudian hasilidari Profile Matching adalah berupa rekomendasi tempat 
menginap beserta koordinatnya yang kemudian ditampilkan menggunakan google MAP API sehingga diperoleh rute terdekat dari posisi pengguna aplikasi ini.

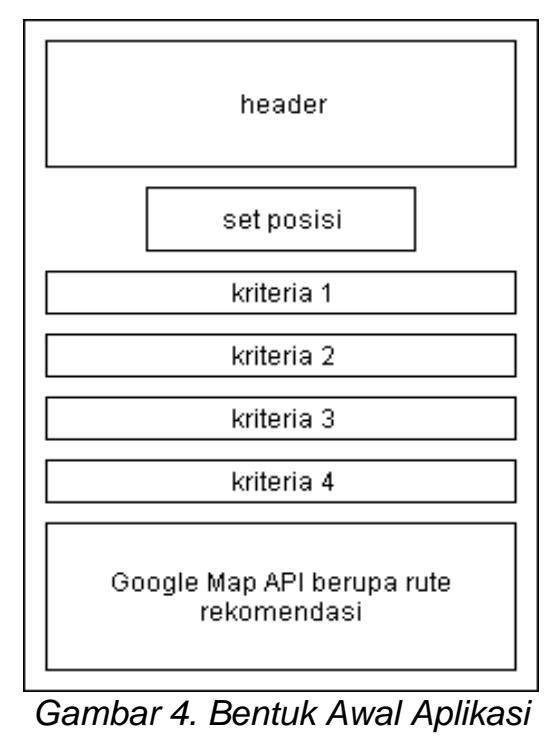

Pada Gambar 4 digambarkan bentuk awal aplikasi yang digunakan oleh user aplikasi pada aplikasi tersebut terdapat slider yang digunakan oleh pengguna untuk memasukan kriteria yang ia inginkan dan setelah kriteria tersebut terisi maka aplikasi akan meminta data dari server untuk kemudian diproses dengan Profile Matching sesuai dengan input kriteria dari pengguna, setelah proses Profile Matching selesai maka program akan mengeluarkan jalur menuju objek dan ulasan mengenai fasilitas disekitar objek yang direkomendasikan.

\subsection{Pembuatan Program}

Tahap ini merupakan proses penulisan program yang merupakan penerjemahan dari bentuk design ke dalam bahasa yang bisa dikenali oleh komputer. Proses ini dilakukan oleh programmer yang akan meterjemahkan data wawancara dan penelitian yang diminta oleh User.

Tahapan inilah yang merupakan tahapan nyata dalam mengerjakan suatu sistem. Setelah pengkodean selesai maka akan dilakukan testing terhadap sistem yang telah dibuat tadi. Tujuan testing adalah menemukan kesalahan-kesalahan terhadap sistem tersebut dan kemudian bisa diperbaiki.

\subsection{Testing}

Pada tahap ini adalah tahap dimana untuk menguji hasil dari implementasi yang telah dilakukan apakah telah sesuai dengan keinginan atau belum. Kemudian mengevaluasi hasil implementasi agar didapatkan hasil yang maksimal dari aplikasi ini. Untuk testing aplikasi ini akan menggunakan metode Black Box guna mengetahui keseluruhan fungsiitelah bekerja dengan baik, dalam artian fitur-fitur yang dicantumkan pada program dapat digunakan.

\subsection{Implementasi dan Pengujian}

Setelah diimplementasikan berupa aplikasi anroid maka perlu dilakukan pengujian guna mengetahui sejauh mana kualitas dari rekomendasi yang dihasilkan serta seberapa tepat panduan rute yang ditampilkan. Analisis akan difokuskan pada rekomendasi dan rute yang dihasilkan oleh Haversine Formula yang diterapkan pada Application Programming Interface Google Map dengan mencocokan antara hasil yang diharapkan pengguna dan hasil yang dikeluarkan, seperti pada Tabel 1.

Tabel 1. Skenario Pengujian

\begin{tabular}{cccc}
\hline No & Model pengujian & Hasil & keterangan \\
\hline \multirow{4}{*}{1} & mencobaimengukur & jarakiantaraidua & terukuridalam \\
& koordinatilatitude & satuanikiloimeter & deskripsiitiapititik latitude \\
& dan longitude
\end{tabular}

REPOSITOR, Vol. 2, No. 6, Juni 2020: 727-736 
longitude yang

diperolehidari google

map denganijarak yang

tidakiterlaluijauh $(100 \mathrm{~m})$

menggunakan metode

haversine formula[2][3].

terkaitidengan

pengujianinomor 1

makaiperluidiuji

2

denganifungsi

estimasiiwaktu

tempuhiyang

disediakanioleh google map[2].

dilakukanipengujian pencarianirute

terpendekidaniwaktu

3

tempuhitercepatiyang

manaipadaipengujian ini google map API

telahimenyediakan

fasilitasiulti rute[2].

4 aplikasi

Estimasiiwaktu tempuhidalam satuanijam, imenit dan detik

hasiliberupaidaftar rekomendasiirute dan waktuitempuh

\author{
hasiliberupa
} deskripsiipengujian mencobaimelakukan perjalananiuntuk mengukuriwaktu tempuhimenggunakan stopwatch

\section{Hasil dan Pengujian}

\subsection{Hasil Implementasi Block Program}

Setelah tahap implementasi block program maka akan diperoleh hasil berupa interface yang tersusun dalam beberapa tampilan pada menu-menu aplikasi. Desain dari user interface yang baik dalam sebuah sistem dapat mempermudah user atau pengguna dalam menggunakan aplikasi tersebut. Interface pada aplikasi ini menggunakan bahasa pemrograman android MIT APP Inventor. Berikut tampilan interface pada sistem yang sudah dibangun.

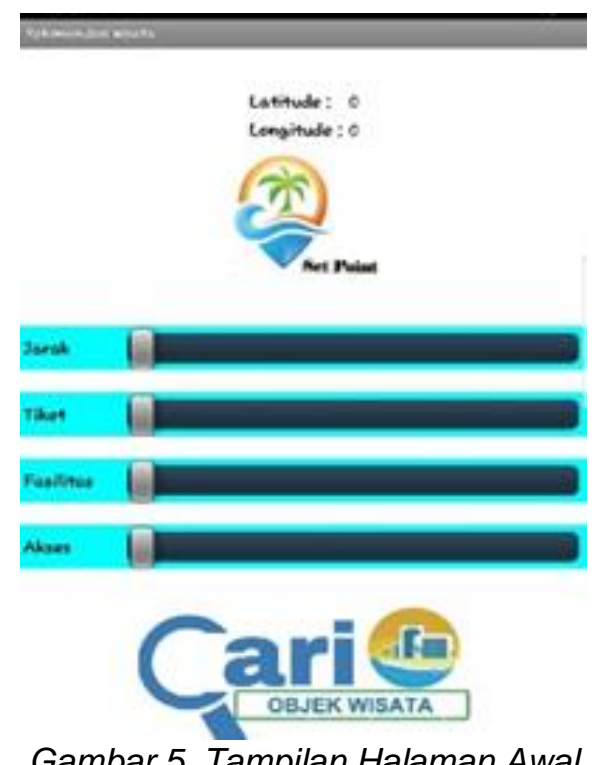

Pada Gambar 5 merupakan tampilan ini adalah halaman depan yang pertamakali diakses oleh pengguna atau user. Terdapat keterangan lokasi dengan Latitide dan Longitude, tombol Set Point untuk mengambil posisi user saat ini, slider-slider untuk menerima input kriteria dari user dan tombol cari untuk memproses semua input yang diterima kedalam profile matching dan dikeluarkan sebagai suatu rekomendasi kepada user. 

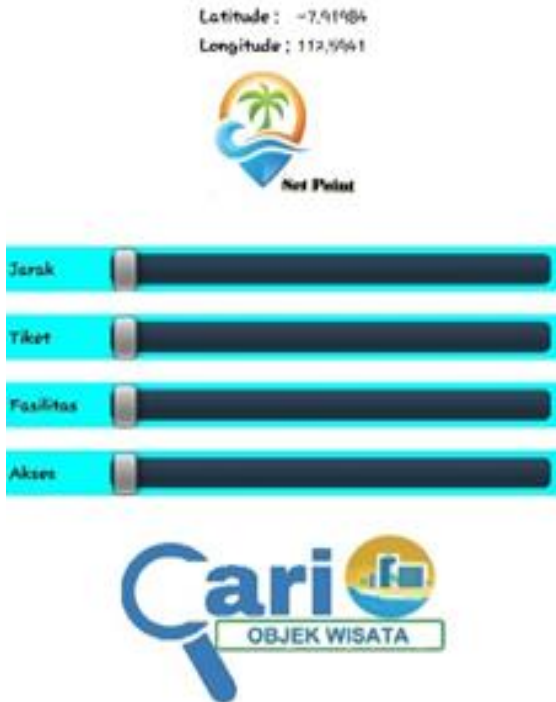

Gambar 6. Tampilan User Memasukan Kriteria

Pada Gambar 6 merupakan proses ketika user sedang memasukan kriteria yang diinginkannya dengan inputan yang harus dipenuhi adalah jarak, harga tiket, akses dan fasilitas.

Pada Gambar 6 merupakan proses ketika user sedang memasukan kriteria yang diinginkannya dengan inputan yang harus dipenuhi adalah jarak, harga dan fasilitas. Pada Gambar 6 user menginginkan jarak yang berkisar 4,4 km dari lokasinya saat ini, harga tiket paling minim, dengan fasilitas paling minim dan dapat diakses dengan kendaraan roda dua, Set point yang dihasilkan adalah Latitude -7.91984 dan Longitude 112.5941, ini merupakan posisi user saat ini yang akan dibandingan dengan input jarak pada perhitungan profile matching.

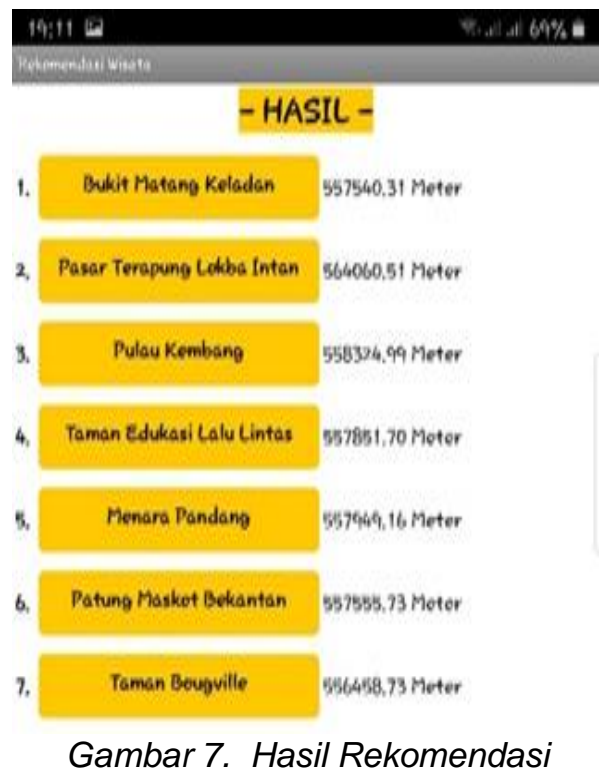

Pada Gambar 7 merupakan bentuk dari tampilan hasil rekomendasi, pada bagian ini user akan memperoleh jarak ke rekomendasi yang dihasilkan, untuk mengetahui rute yang ditempuh user cukup mengklik hasil rekomendasi yang telah diurutkan dari yang paling dekat ke terjauh dan akan memunculkan rute dalam format Google map. 

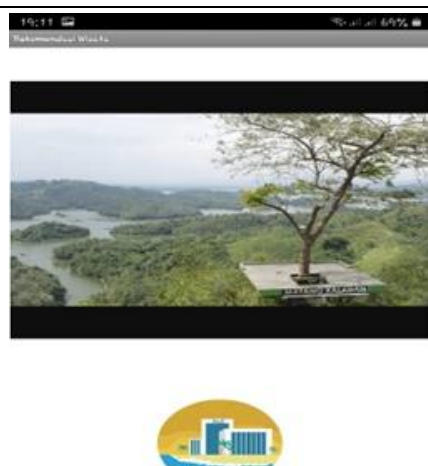

Gambar 8. Rute Rekomendasi

Pada Gambar 8 merupakan bentuk dari tampilan rute dalam Google map yang dapat digunakan oleh user sebagai panduan menuju lokasi yang direkomendasikan, dengan menggunakan Google map ini akan mempermudah userkarena telah disediakan panduan suara.

\subsection{Pengujian Dengan Metode Blackbox}

Pada tahap ini dilakukan pengujian fungsional dengan menggunakan black box testing. Pengujian ini dilakukan untuk mengetahui apakah aplikasi ini sudah sesuai rancangan dan kebutuhan atau masih diperlukan perubahan dan penyempurnaan. Pengujian ini difokuskan pada skenario pengujian aplikasi yang ditunjukkan pada Tabel 2 dengan tujuan untuk mengetahui fungsi-fungsi aplikasi berdasarkan urutan penggunaan dan untuk mengevaluasi fungsi dari setiap tombol yang diberikan, apakah sudah sesuai dengan perancangan.

Tabel 2. Skenario pengujian BlackBox

\begin{tabular}{|c|c|c|}
\hline No & Test & Hasil Yang Diharapkan \\
\hline 1 & $\begin{array}{l}\text { Menjalankan program untuk } \\
\text { menampilkan halaman awal aplikasi }\end{array}$ & $\begin{array}{l}\text { Program dapat menampilkan } \\
\text { halaman awal aplikasi }\end{array}$ \\
\hline & Memasukan nilai kriteria dari user & Mampu melakukan input \\
\hline 2 & $\begin{array}{l}\text { dengan slider, slider ini terdiri dari kriteria } \\
\text { jarak, harga, fasilitas dan akses }\end{array}$ & $\begin{array}{l}\text { kriteria dengan menggeser } \\
\text { slider pada tampilan aplikasi }\end{array}$ \\
\hline & $\begin{array}{l}\text { Uji coba User Memasukan Set Point, set } \\
\text { point merupakan pengambilan koordinat }\end{array}$ & $n t$ \\
\hline 3 & $\begin{array}{l}\text { user aplikasi berdasarkan data GPS yang } \\
\text { digunakan untuk mengukur preferensi } \\
\text { jarak dari user ke data-data koordinat } \\
\text { tempat rekomendasi di database }\end{array}$ & $\begin{array}{l}\text { dan memunculkan koordinat } \\
\text { GPS berupa latitude dan } \\
\text { longitude user }\end{array}$ \\
\hline 4 & $\begin{array}{l}\text { Menampilkan hasil rekomendasi setelah } \\
\text { user menekan tombol "Cari" }\end{array}$ & $\begin{array}{l}\text { Menampilkan hasil } \\
\text { rekomendasi wisata }\end{array}$ \\
\hline 5 & $\begin{array}{l}\text { Menampilkan foto dan keterangan hasil } \\
\text { rekomendasi setelah user menekan salah } \\
\text { satu list hasil rekomendasi }\end{array}$ & $\begin{array}{l}\text { Menampilkan foto dan } \\
\text { keterangan hasil rekomendasi. }\end{array}$ \\
\hline 6 & $\begin{array}{l}\text { Menampilkan rute ke rekomendasi } \\
\text { dengan menggunakan Google Map } \\
\text { setelah user menekan tombol "rute" }\end{array}$ & $\begin{array}{l}\text { Menampilkan rute ke hasil } \\
\text { rekomendasi pada Google Map }\end{array}$ \\
\hline
\end{tabular}

Pada Tabel 2 merupakan urutan atau sekenario pengujian blackbox aplikasi rekomendasi wisata di Banjarmasin dengan metode profile matching berbasis android, tujuan pengujian tersebut adalah untuk mengetahui hasil dari setiap fungsi yang disebutkan pada bagian perancangan. Sekenario yang dipaparkan dalam Tabel 2 dimulai dari user membuka aplikasi sampai dengan user memperoleh rekomendasi dan menampilkan rute menuju rekomendasi.

\section{Kesimpulan}

Dilihat dari penelitian di atas dapat disimpulkan aplikasi yang di bangun akan bisa memberikan rekomendasi tempat pariwisata terdekat dari set point yang telah di set oleh user untuk mencari rute terpedek dan rute alternatif kedalam bahasa pemrograman berbasis android, 
sehingga menghasilkan rekomendasi tempat pariwisata dalam radius tertentu yang ditampilkan pada Google Map API.

\section{Referensi}

[1] Turban, Efraim, Jay E. Aronson, and Ting-Peng Liang. "Sistem Pendukung Keputusan dan Sistem Cerdas." Terjemahan Dwi Prabantini. Yogyakarta: Andi (2005).

[2] Setiawan, Cahyo. "Pembangunan Aplikasi Traveling Guide Kota Bogor Menggunakan Google MAP API." (2014).

[3] Hafsah, Mrs, Frans Richard Kodong, and Alain Julian. "Sistem Pendukung Keputusan Penentuan Hotel Dengan Menggunakan Metode Promitee dan AHP." Seminar Nasional Informatika 2011. 2011.

[4] Chairi, A., Putri, R., \& Fanani, L. 2017 Agu 30. Rekomendasi Tempat Wisata Kota Malang Menggunakan Metode Profile Matching Dan Saran Rute Menggunakan Floyd Warshall Berbasis Android. Jurnal Pengembangan Teknologi Informasi dan IImu Komputer. [Online] 2:5

[5] Arisandi, Arisandi, Muh Ihsan Sarita, and S. Sagala La Ode Hasnuddin. "Sistem Penunjang Keputusan Pemilihan Hotel di Kota Kendari Berbasis Web Menggunakan Metode Fuzzy Tahani." semanTIK 2.1 (2016). 